\title{
Efficacy of Nebulized Magnesium Sulphate in the Treatment of Acute Bronchial Asthma Compared to Nebulized Salbutamol: A Randomized Control Trial
}

\author{
ZANNAT-UL-SARMIN ${ }^{1}$, SAYEEDA ANWAR ${ }^{2}$, TAFAZZAL HOSSAIN KHAN ${ }^{3}$, MD.ABID HOSSAIN \\ MOLLAH $^{4}$, ROKEYA KHANAM ${ }^{5}$, SHAH ABDULLAH AL BAKI ${ }^{6}$
}

\begin{abstract}
Background: Nebulized salbutamol is commonly used in treatment of asthma in children. The use of nebulized MgSO4 is one of the different treatment options available during acute exacerbation.

Objective: To compare the efficacy of nebulized $\mathrm{MgSO}_{4}$ with nebulized salbutamol in the treatment of acute asthma in children.

Materials and method: This randomized controlled study was conducted in Dhaka Medical College Hospital between January to December 2016. Children of 7-12 years with acute exacerbation of asthma were randomized into study group- $A$ (MgSO4 group, $n=30$ ) and control group- $B$ (Salbutamol group, $n=30$ ). Children of both groups were treated with serial nebulization thrice at 20 minute intervals by either $2.4 \mathrm{ml}$ (4\% MgSO4, $96 \mathrm{mg}$ ) or salbutamol ( $0.15 \mathrm{mg} / \mathrm{kg}$ minimum $2.5 \mathrm{mg})$ with $2.5 \mathrm{ml}$ of isotonic normal saline.

Results: The mean final PEFR were not different between the two groups (275.0 $\pm 41.42 \mathrm{~L} / \mathrm{min}$ in $\mathrm{MgSO}_{4}$ group and $263 \pm 36.17 \mathrm{~L} / \mathrm{min}$ in salbutamol group). The increase in PEF was statistically significant and comparable in both groups (by $35.1 \%$ in the $\mathrm{MgSO}_{4}$ group and by $42.1 \%$ in the salbutamol group). Fischl score improvement was comparable and significant in both groups (4.31 to 0.43 in $\mathrm{MgSO}_{4}$ group and 4.29 to 0.76 in salbutamol group). Statistically significant increase in oxygen saturation and reduction of heart rate was found in $\mathrm{MgSO}_{4}$ group without any side effects. Nebulized $\mathrm{MgSO}_{4}$ was found having significant bronchodilator effect which is comparable to salbutamol.
\end{abstract}

Conclusion: Nebulized $\mathrm{MgSO}_{4}$ was found equally effective as nebulized salbutamol in the treatment of severe acute asthma in children.

Keywords: Nebulized magnesium sulphate $\left(\mathrm{MgSO}_{4}\right)$, salbutamol, acute asthma, peak expiratory flow rate (PEFR), Fischl index.

1. Registrar, Paediatric Nephrology, Dhaka Medical College \& Hospital, Dhaka.

2. Professor \& Head, Department of Paediatrics, Dhaka Medical College \& Hospital, Dhaka.

3. Associate Professor, Department of Neonatology, Dhaka Medical College \& Hospital, Dhaka.

4. Professor \& Head, Department of Paediatrics, BIRDEM-2, Dhaka.

5. Associate Professor, Department of Paediatrics, Dhaka Medical College \& Hospital, Dhaka.

6. Junior Consultant, Paediatrics

Correspondence: Dr. Zannat-ul-Sarmin, Registrar, Paediatric Nephrology, Dhaka Medical College \& Hospital, Dhaka. Contact no-01714686122, E-mail: drsarmin37@gmail.com

Received: 14/10/2018

Accepted: 19/12/2019

\section{Introduction}

Asthma is one of the most common chronic inflammatory lung diseases in children. The prevalence of childhood asthma varies from $10 \%$ to $30 \%$. ${ }^{1,2}$ Different studies show that asthma is prevalent up to one out of three children worldwide. ${ }^{3,4}$ Intermittent acute exacerbations are common and are characterized by episodes of cough, respiratory distress, dyspnea, wheeze. ${ }^{5,6}$ Asthma causes personal and social burden, due to stagger costs to the patient and health care system. ${ }^{7}$ Asthma exacerbations are associated with airways 
obstruction and assessed by peak expiratory flow rate (PEFR) or forced expiratory volume (FEV1) measurement. ${ }^{8}$ Clinically, patients with acute severe asthma appear seriously dyspneic at rest, unable to talk with sentences or phrases, are agitated, and sit upright. 9,10 So early treatment of asthma exacerbations should be the best strategy for management. ${ }^{11}$ Standard treatments for asthma include short-acting bronchodilator ( $\beta 2$-agonists), inhaled anticholinergic agents, and corticosteroids, in addition to general management. ${ }^{12-15}$

Since $30 \%$ of patients in the emergency department failed to respond adequately to inhaled $\beta_{2}$-agonist and treatment costs are increasing. ${ }^{16}$ Recent two meta-analyses found that IV magnesium sulphate $\left(\mathrm{MgSO}_{4}\right)$ decreases asthma hospitalization in children by $30 \% .{ }^{17-20}$ Randomized control trial is not available on the efficacy of nebulized $\mathrm{MgSO}_{4}$ alone in acute asthma although this drug appears to be effective and safe to administer to a patient experiencing asthma exacerbation. ${ }^{21,22}$ Intravenous magnesium is contraindicated in patient with impaired renal function. $\mathrm{MgSO}_{4}$ nebulization may be used in that condition because high concentration of magnesium can be locally delivered without any systemic side effect. ${ }^{23}$ So this study, has been aimed to see the efficacy of nebulized $\mathrm{MgSO}_{4}$ as a bronchodilator in the management of acute bronchial asthma.

\section{Materials and Method}

This randomized clinical study was carried out in the department of Pediatrics, Dhaka Medical College Hospital, Dhaka, between January 2016 to December 2016 in children who were admitted with clinical presentation of acute bronchial asthma. Children between $7-12$ years of age who fulfilled the criteria of acute asthma according to national asthma guidelines were enrolled in this study. Patients who had any evidence of respiratory tract infection or suppurative lung diseases, any history or evidence of cardiac, renal or hepatic dysfunction, use of short acting bronchodilator within 8 hours or long acting bronchodilator within-24 hours and use of steroid within 7 days were excluded from the study.

Among eighty-three study population who were screened over the study period, only 60 patients were selected by inclusion criteria, among these half of the patients were in group- $A$ (magsulph group $n=30$ ) and rest of the patients were in group-B (salbutamol group $n=30$ ) by randomization, which was done by lottery method.

Relevant history and physical examination findings were recorded in a pretested questionnaire. The parameters were measured and recorded on admission as baseline characteristics. A clinical severity score (Fischl scores), was also used to measure clinical severity and improvement. The parameters which Fischl scores take into account are dyspnea, accessory muscle use, wheeze, respiratory rate $>30$ breaths/ min, heart rate $>120$ beats/ min, Pulse pressure $>18 \mathrm{~mm} \mathrm{Hg}$ and PEF < $120 \mathrm{~L} / \mathrm{min}$. Each score carries 1 point and more than 4 points indicate severe asthma. All patients were monitored for arrhythmias, hypotension, respiratory depression and loss of deep tendon reflexes before and after administration of each dose, and were under continuous monitoring for oxygen saturation with pulse oximeter.

Patients were randomized to receive treatment with nebulization of either salbutamol $(0.15 \mathrm{mg} / \mathrm{kg}$ minimum dose $2.5 \mathrm{mg}$ ) with $2.5 \mathrm{ml}$ of isotonic normal saline or $2.4 \mathrm{ml}$ (4\% MgSo 4 solution, $96 \mathrm{mg}$ ) on 3 times at 20 minute intervals in both groups.

Patients who were not showing any PEFR improvement at the end of the one hour study period have been given supplemental treatment immediately. Supplemental treatment administered consisted of salbutamol nebulization, regular doses of IV/oral steroids etc.

\section{Results:}

The age of the patients in MgSO4 group was $9.42 \pm 1.67$ years, whereas, in control group, it was $8.65 \pm 1.97$ years. In the isotonic magnesium sulfate 15 patients were male, and 15 were female. On the other hand, in the control group, 19 were male and 11 females. In MgSO4 group mean height was 134.0 $\pm 8.01 \mathrm{~cm}$, and mean weight was $26.22 \pm 8.29 \mathrm{~kg}$ on other hand in control group it was $132.0 \pm 7.15 \mathrm{~cm}$ and $24.47 \pm 6.04 \mathrm{~kg}$, respectively. The duration of asthma was $2.05 \pm 0.74$ years in the magnesium sulfate group and $0.74 \pm 0.13$ years in the control group. Four patients in group-A, and one patient in group-B required such supplemental treatment. In all cases, the differences between the two groups were not statistically significant, except the duration of asthma. (Table-I) 
Table-I

Baseline characteristics of the children in both groups $(n=60)$

\begin{tabular}{|c|c|c|c|}
\hline \multirow[t]{2}{*}{ Baseline characteristics } & Group A $(n=30)$ & Group B $\quad(n=30)$ & $p$ value \\
\hline & Mean $\pm S D$ & \multicolumn{2}{|l|}{ Mean \pm SD } \\
\hline \multicolumn{4}{|l|}{ Age } \\
\hline$($ Mean $\pm S D)$ & $9.42 \pm 1.67$ & $8.65 \pm 1.97$ & $0.107^{\mathrm{ns}}$ \\
\hline \multicolumn{4}{|l|}{ Sex } \\
\hline Male & $15(50.0 \%)$ & $19(63.3 \%)$ & $0.297^{\mathrm{ns}}$ \\
\hline Female & $15(50.0 \%)$ & $11(36.7 \%)$ & \\
\hline Height (cm) & $134.0 \pm 8.01$ & $132.0 \pm 7.15$ & $0.312^{\text {ns }}$ \\
\hline Weight (kg) & $26.22 \pm 8.29$ & $24.47 \pm 6.04$ & $0.354^{\mathrm{ns}}$ \\
\hline Duration of asthma (yrs) & $2.05 \pm 0.74$ & $0.74 \pm 0.13$ & $0.001^{\mathrm{s}}$ \\
\hline Family history of asthma & $25(83.3 \%)$ & $23(76.7 \%)$ & $0.518^{\mathrm{ns}}$ \\
\hline Newly diagnosed asthma & $1(3.3 \%)$ & $0(0.0 \%)$ & $0.313^{\text {ns }}$ \\
\hline
\end{tabular}

Unpaired student's t-test was used to performed in quantitative data and Chi-square was used to perform in qualitative data.

Table-II

Clinical parameters of the patients of two groups $(n=60)$

\begin{tabular}{|c|c|c|c|c|}
\hline \multirow[t]{2}{*}{ Parameters } & \multicolumn{2}{|c|}{ Group A $(n=30)$} & \multicolumn{2}{|c|}{ Group B $(n=30)$} \\
\hline & No. & $(\%)$ & No. & $(\%)$ \\
\hline \multicolumn{5}{|l|}{ Symptoms } \\
\hline \multicolumn{5}{|c|}{ Breathlessness during } \\
\hline Talking & 28 & $(93.3)$ & 26 & $(86.7)$ \\
\hline Resting & 2 & $(6.7)$ & 4 & (13.3) \\
\hline \multicolumn{5}{|c|}{ Physical exhaustion } \\
\hline Yes 1 & $(3.3)$ & 2 & $(6.7)$ & \\
\hline No 29 & (96.7) & 28 & (93.3) & \\
\hline \multicolumn{5}{|l|}{ Talks in } \\
\hline Phrases & 28 & (93.3) & 26 & $(86.7)$ \\
\hline Words & 2 & $(6.7)$ & 4 & (13.3) \\
\hline \multicolumn{5}{|l|}{ Signs } \\
\hline \multicolumn{5}{|l|}{ Wheeze } \\
\hline Loud & 25 & (83.3) & 27 & $(90.0)$ \\
\hline Very loud & 5 & $(16.7)$ & 3 & $(10.0)$ \\
\hline \multicolumn{5}{|c|}{ Use of accessory muscle } \\
\hline No 2 & $(6.7)$ & 2 & $(6.7)$ & \\
\hline Yes 28 & (93.3) & 27 & $(90.0)$ & \\
\hline Prominent & 0 & $(0.0)$ & 1 & $(3.3)$ \\
\hline \multicolumn{5}{|c|}{ Pulse (per minute) } \\
\hline $100-160$ & 30 & $(100.0)$ & 30 & $(100.0)$ \\
\hline \multicolumn{5}{|l|}{ PEFR (\%) } \\
\hline $40 \%$ to $60 \%$ & 30 & $(100.0)$ & 30 & $(100.0)$ \\
\hline \multicolumn{5}{|l|}{$\mathrm{SpO}_{2}$} \\
\hline $94 \%-90 \%$ & 29 & $(96.7)$ & 28 & (93.3) \\
\hline$<90 \%$ & 1 & $(3.3)$ & 2 & (6.7 \\
\hline
\end{tabular}

One patient from MgSO4 group and 2 from the control group were exhausted during the presentation. Twenty-eight patients talked in phrases and 2 in words in the magnesium sulfate group, whereas 26 patients talked in phrases and 4 in words in the control group. In the magnesium sulfate group, loud and very loud wheeze was present in 25 and 5 patients, respectively, while in the control group, they were found in 27 and 3 patients. The differences were not statistically significant in all the parameters in both the group. In all cases, pulse rate was within100160 per minute, and PEFR was $40 \%$ to $60 \%$ of the predicted value. In magnesium sulfate group and control group 28 and 26 patients respectively were breathless during talking while 2 and 4 patients were breathless during resting. (Table-II)

The mean final PEFR were not significantly different between the two groups $(275.0 \pm 41.42 \mathrm{~L} / \mathrm{min}$ in the $\mathrm{MgSO}_{4}$ group versus $263.06 \pm 36.17 \mathrm{~L} / \mathrm{min}$ in the salbutamol group). A correction was made for the difference in the basal PEFR of the two groups and there was no statistically significant difference in the final bronchodilator response $(p=0.240)$. Similar improvement in the two groups was found as increase in PEFR by $35.1 \%$ predicted in $\mathrm{MgSO}_{4}$ and by $42.1 \%$ predicted in the salbutamol group $(p=0.078)$. The Fischl index improvement in the $\mathrm{MgSO}_{4}$ group (4.31 to 0.43) was significant and similar to that seen in the salbutamol group (4.29 to 0.76 ). The mean respiratory rate and the mean heart rate were not statistically significantly different $(p>0.05)$ between the two groups. There was a significant increase in oxygen saturation $\left(\mathrm{SpO}_{2}\right)$ in group A and not significant in group B.(Table-III) 
Table-III

Improvement table of specific intervention in the two groups $(n=60)$

\begin{tabular}{|c|c|c|c|}
\hline & Group A $(n=30)$ & Group B $(n=30)$ & $p$ value \\
\hline & Mean $\pm S D$ & Mean $\pm S D$ & \\
\hline \multicolumn{4}{|l|}{ PEF L/min } \\
\hline Basal & $167.3 \pm 19.11$ & $163.67 \pm 14.49$ & 0.239 \\
\hline Final & $275.0 \pm 41.42$ & $263.06 \pm 36.17$ & 0.240 \\
\hline \multicolumn{4}{|l|}{ PEF \% pred } \\
\hline Basal & $41.88 \pm 18.70$ & $34.35 \pm 12.59$ & 0.072 \\
\hline Final & $77.03 \pm 31.89$ & $76.45 \pm 22.13$ & 0.935 \\
\hline Increase in PEF \% & $35.1 \pm 14.33$ & $42.1 \pm 15.9$ & 0.078 \\
\hline \multicolumn{4}{|l|}{ Fischl index } \\
\hline Basal & $4.31 \pm 1.35$ & $4.29 \pm 1.64$ & 0.595 \\
\hline Final & $0.43 \pm 0.89$ & $0.76 \pm 1.25$ & 0.243 \\
\hline Improvement in Fischl index & $3.88 \pm 1.74$ & $3.53 \pm 1.87$ & 0.456 \\
\hline \multicolumn{4}{|l|}{ Respiratory rate breaths/min } \\
\hline Basal & $31.31 \pm 6.51$ & $30.94 \pm 6.86$ & 0.831 \\
\hline Final & $22.87 \pm 2.82$ & $22.76 \pm 6.34$ & 0.931 \\
\hline \multicolumn{4}{|l|}{ Heart rate beats/min } \\
\hline Basal & $112.50 \pm 12.57$ & $110.41 \pm 16.12$ & 0.577 \\
\hline Final & $99.37 \pm 12.01$ & $103.43 \pm 15.39$ & 0.261 \\
\hline$p$ value & $0.002^{*}$ & 0.092 & \\
\hline \multicolumn{4}{|l|}{ Oxygen saturation $\left(\mathrm{SpO}_{2}\right)$} \\
\hline Basal & $92.18 \pm 2.37$ & $95.47 \pm 8.36$ & $0.044^{*}$ \\
\hline Final & $96.13 \pm 0.93$ & $95.62 \pm 1.41$ & 0.104 \\
\hline$p$ value & $<0.001^{*}$ & 0.923 & \\
\hline
\end{tabular}

Table-IV

Different parameters of patients in two groups

\begin{tabular}{lccc}
\hline & Group A ( $\mathrm{n}=30)$ & Group B $(\mathrm{n}=30)$ & p value \\
& No. $(\%)$ & No. $(\%)$ & \\
\hline Atopy & $2(6.7 \%)$ & $1(3.3 \%)$ & 0.553 \\
Accessory muscle working & $4(13.3 \%)$ & $1(3.3 \%)$ & 0.161 \\
Need for supplemental therapy & $4(13.3 \%)$ & $1(3.3 \%)$ & 0.161 \\
\hline
\end{tabular}

There were four patients in group- $A$, and one patient in group- $B$ who presented with a severe attack $(\mathrm{PEF}<50 \%)$. They were distressed with working accessory respiratory muscles. They needed supplemental therapy in the form of frequent salbutamol nebulization and oral/IV steroid. (Table-IV)
One of the patients in the MgSO4 group developed mild transient hypotension, which resolved spontaneously. A similar case of hypotension was also seen in the salbutamol group, and two patients developed fine tremors of the hand, and one experienced palpitation. (Table-V) 
BANGLADESH J CHILD HEALTH 2020; VOL 44 (1) : 28

Table- V

Side effects of drugs in two groups

\begin{tabular}{lccc}
\hline & $\begin{array}{c}\text { Group A } \\
(\mathrm{n}=30)\end{array}$ & $\begin{array}{c}\text { Group B } \\
(\mathrm{n}=30)\end{array}$ & $\begin{array}{c}\mathrm{p} \\
\text { value }\end{array}$ \\
& No. $(\%)$ & No. $(\%)$ & \\
\hline Hypotension & $1(3.3 \%)$ & $1(3.3 \%)$ & 1.00 \\
Tremor & $0(0 \%)$ & $2(6.6 \%)$ & 0.150 \\
Palpitation & $0(0 \%)$ & $1(3.3 \%)$ & 0.313 \\
\hline
\end{tabular}

\section{Discussion}

In majority cases acute asthma improves with an short-acting beta-agonist inhalation, such as salbutamol, a commonly used asthma medication that relaxes airway muscles and dilates or enlarges breathing passages. Severe asthma requires additional treatment such as corticosteroids, MgSO4, and mechanical ventilation according to severity.

The results of the study show that the use of $\mathrm{MgSO}_{4}$ by nebulization results in improvements in clinical condition, an increase in peak expiratory flow rate (PEFR), reduction in heart rate (HR), reduction in respiratory rate $(R R)$ and improvement in oxygen saturation $\left(\mathrm{S}_{\mathrm{P}} \mathrm{O}_{2}\right)$. MgSO4 has a significant bronchodilator effect in acute bronchial asthma, which is comparable to nebulized salbutamol.

In the mean final PEF, there were no difference between the groups $\left(275.0 \pm 41.42 \mathrm{~L} / \mathrm{min}\right.$ in $\mathrm{MgSO}_{4}$ group and $263 \pm 36.17 \mathrm{~L} / \mathrm{min}$ in salbutamol group). The increase in PEFR percentage was statistically significant and comparable in both groups (by $35.1 \%$ predicted in the $\mathrm{MgSO}_{4}$ group and by $42.1 \%$ predicted in the salbutamol group. The result agree with the result of the randomized double blind control study of Mangat et al. and also agreed with a single blind study conducted by T Tanmaya et al. ${ }^{21,24}$

Statistically significant reduction of heart rate was observed in $\mathrm{MgSO}_{4}$ group but not in salbutamol group (table-III) because salbutamol causes stimulation of B2-receptors of the heart. Similar reduction of heart rate was also found in some studies like Mangat et al and Abdelnabiet al. ${ }^{21,25}$ This finding illustrates the fact that nebulized $\mathrm{MgSO}_{4}$ can be used safely in cardiac patients.

For an effective therapeutic dose, serial and repetitive doses of $\mathrm{MgSO}_{4}$ were used. Nebulized $\mathrm{MgSO}_{4}$ nebulization showed bronchodilator effect which was clinically and statistically significant. Same effect was
Efficacy of Nebulized Magnesium Sulphate in the Treatment

seen in both groups on comparison of the Fischl indices. (table-III). There was statistically significant increase in oxygen saturation $\left(\mathrm{SpO}_{2}\right)$ in $\mathrm{MgSO}_{4}$ group (table-IV) which agreed with the studies conducted by Abdelnabi et al and Tanmaya et al. ${ }^{24,25}$

However, during one hour follow-up only one patient in $\mathrm{MgSO}_{4}$ group developed mild transient hypotension which resolved spontaneously, a similar case of hypotension was also seen in the salbutamol group. Two patients in the salbutamol group developed fine tremor of hand, and one developed palpitation. No serious side effects following magnesium sulphate nebulization also observed by studies conducted by Tanmayaet al and Sarhan et al. ${ }^{12,24}$ Regarding hospital stay there was statistically no significant difference between two groups.

The present conclusions, therefore, differ from the opinion of Chande et al. ${ }^{26}$ in that the inhalational route did not adversely affect the action of $\mathrm{MgSO}_{4}$. This finding is supported by the result of Mangat et al, Rolla et al, T Tanmaya et al. and HA Sarhan et al. in their study. $22,21,24,27$

$\mathrm{MgSO}_{4}$ nebulization may be an adjunct to $\beta_{2}$-agonists in treating acute asthma, as also suggested by Bloch et al, Haqq et al, Mollick et al, and Mahajan et al. studies. In this study $\mathrm{MgSO}_{4}$ nebulization showed low response in severe cases may be due to the lower dose used ( $96 \mathrm{mg} \times 3$ doses), compared with the higher dose used in the intravenous studies (1.22g). 29,30

\section{Conclusion}

In severe acute asthma, nebulized magnesium sulphate and nebulized salbutamol is equally effective, which is evident by clinical improvement, improvement in oxygen saturation and duration of hospital stay.

\section{Recommendations}

Large scale multicenter double blind randomized control trial study can be conducted to further validate the results.

\section{References}

1. Morell F, Genover T, Reyes L, Benaqueb E, Rogera L, Ferrera J. Monitoring of asthma outpatients after adapting treatment to meet international guideline. Archivos de Bronconeumologia. 2007; $43: 29-35$. 
2. Refaat S, Aref $\mathrm{H}$. Acute asthma in emergency department, prevalence of respiratory and nonrespiratory symptoms. Egypt J Chest Dis Tuberc. 2014; 63:771-6.

3. Annesi-Maesano I. Epidemiology of asthma in the world and in France. Rev Prat. 2011;61:329-35.

4. Shan Z, Rong Y, Yang W. Intravenous and nebulized magnesium sulfate for treating acute asthma in adult and children : a systematic review and metaanalysis. Respir Med.2013;107: 321-30.

5. Asher MI, Montefort S, Bjorksten B, lai CK, Strachan DP, Weiland SK, et al. Worldwide time trends in the prevalence of symptoms of asthma, allergic rhinoconjunctivitis and eczema in childhood: ISAAC phases one and three repeat multicountrycrosssectional surveys. Lancet 2006; 368:738-43.

6. Masoli M, Fabian D, Holts, Beasley R. Global initiative for asthma (GINA) program: the global burden of asthma: executive summary of the GINA dissemination committee report. Allergy 2004; 59:468-78.

7. Blitz M, Blitz S, Hughes R, Diner B, Beasley R, Knopp J,et al. Aerosolized magnesium sulfate for acute asthma: a systematic review. Chest.2005;128: 337-44.

8. Busse WW, Banks-Schlegel S, Wenzel SE. Pathophysiology of severe asthma, J. Allergy Clin. Immunol.2000;106:1033-42.

9. Spyros P, Anastasia K, Katerina M. Clinical review: Severe asthma. Critical Care.2002; 6:30-44.

10. National Guidelines Asthma \& COPD. Asthma Association Bangladesh.2016; Available at:Web:www.asthmabd.net.

11. Nalin CK. Acute severe asthma. Sri Lanka Journal of Child Health.2011;40:18-25.

12. Sahran HA, Omar HEG, Ali MA, Youssef NA. The efficacy of nebulized magnesium sulfate alone and in combination with salbutamol in acute asthma. Drug Design, Development and Therapy.2016;10: 1927- 33.

13. Bateman E, Hurd S, Barnes PJ, Bousquet J, Drazen JM, Fitz GM, et al. Global strategy for asthma management and prevention: GINA executive summary. Eur Respir J.2008;31:143-78.

14. Siegel D, Sheppard D, Gelb A, Weinberg P. Aminophylline increases the toxicity but not the efficacy of an inhaled beta-adnergic agonist in the treatment of acute exacerbations of asthma. Am Rev Respir Dis.1985;132:283-6.

15. Talukder T, Singhal P, Jain A, Kumar R, Gaur SN. Inhaled magnesium sulfate in the treatment of severe asthma. Indian J Allergy Asthma Immunol. 2005;19:29-35.
16. Hodgkin JE .United States audit of asthma therapy.Chest.1986;90:62S-66S.

17. Muhammed S, GoodacreS. Inravenous and nebulized magnesium sulphate for acute asthma: systemic review and meta-analysis. Emerg Med J.2007; 24(12):830-2.

18. Cheuk DK, Chan TC, Lee SL. A meta-analysis on intravenous magnesium sulphate for treating acute asthma. Arch Dis child.2005; 90:74- 7.

19. Suchuh S, Macias C, Freedman SB, Plint AC, Zorc JJ, Bayay L. North American practice patterns of intravenous magnesium therapy in severe acute asthma in children. Acad Emerg Med.2010;17: 1189-96.

20. Singhis V, Gupta G. Pediatric emergencies at a tertiary care hospital in India.J Trop pediatr. 2003;49: 207-11..

21. Mangat HS, D Souza GA, Jacob MS. Nebulized magnesium sulphate versus nebulized salbutamol in acute bronchial asthma: a clinical trial. Eur Respir J.1998;12: 341-4.

22. Rowe BH, Bretzlaff JA, Bourdon C, Bota GW, Camargo CA Jr. Magnesium sulfate for treating exacerbations of acute asthma in the emergency department.Cochrane Database Syst Rev.2004;3.

23. Yan $\mathrm{YY}, \mathrm{Ng} \mathrm{MH}$. Review of the role of magnesium sulphate in the management of asthma patient at A\& E setting. Hong Kong J Emerg Med.2003;10: 37-42.

24. Tanmaya T, Pankaj S, Ankit J. Inhaled magnesium sulphate in the treatment of severe asthma.Indian J. Allergy Asthma Immunol. 2005;19:29-35.

25. Abdelnabi EA, Kamel MM, Ali AE. Nebulized magnesium sulphate versus nebulized salbutamol in acute bronchial asthma. Egypt J Chest Dis Tuberc. 2012; 61:29-34.

26. Chande VT, Skoner, DP. A trial of nebulized magnesium sulphate to reverse bronchospasm in asthmatic patients. Ann Emerg Med.1992;.21: 1111-5.

27. Rolla G, Bucca C, ArossaW, Bugiani M. Magnesium attenuates methacholine induced bronchoconstriction in asthmatics. Magnesium. 1987;6:201-4.

28. Bloch H, Silverman R, Mancherje N, Grant S, Jagminas L, Scharf SM. Intravenous magnesium sulphate as an adjunct in the treatment of acute asthma. Chest.1995;107: 1576-81.

29. Haq MA, Rahman MH, Khanam S, Mannan MA. Efficacy of nebulized magnesium sulfate in the treatment of acute exacerbation of asthma in children. Bangladesh J Pharmacol.2006;1: 72-80.

30. Mahajan P, Haritos D, Rosenberg N, Thomas R. Comparison of nebulized magnesium plus albuterol to nebulized albuterol plus saline in children with mild to moderate asthma. J Emerg Med. 2004;7: 21-5. 